\title{
Infected Radicular Cyst of Deciduous Second Molar Mimicking Dentigerous Cyst of Second Premolar in a Young Child: A Rare Entity
}

\author{
Shweta Kajjari ${ }^{1}$, A Gowtham², Priya Meharwade ${ }^{3}$, Chaitanya Uppin ${ }^{4}$, Shivayogi M Hugar ${ }^{5}$, Chandrashekhar Badakar ${ }^{6}$
}

\begin{abstract}
Radicular cysts are the most common cystic lesions in the oral cavity. Radicular cysts have a rare occurrence in the primary dentition. Radicular cysts arising from deciduous teeth are reported to occur in the age range of 3-19 years with a male predominance. The etiological factor is long-standing dental caries and dental trauma. The present case report describes the inflammatory radicular cyst involving the deciduous mandibular second molar. Surgical management includes enucleation of the cyst along with mandibular second premolar in a 5-year-old female patient. The surgical cavity was closed by an obturator appliance to maintain the patency. Eventful healing was seen after 3 months of follow-up. Keywords: Dentigerous cyst, Enucleation, Obturator, Radicular cyst. International Journal of Clinical Pediatric Dentistry (2021): 10.5005/jp-journals-10005-1954
\end{abstract}

\section{INTRODUCTION}

Different types of inflammatory lesions are seen in the oral cavity of children. Odontogenic cysts represent the most common form of cystic lesions affecting the maxillofacial region. A radicular cyst is the most common cyst occurring in the jaw. Radicular cysts are defined as a cyst arising from epithelial residues (cell rests of Malassez) in the periodontal ligament as a consequence of inflammation, usually following the death of the dental pulp. ${ }^{1}$

Among odontogenic cysts, radicular cysts comprise about $60 \%$ but are very rare in the primary dentition. ${ }^{2}$ Radicular cysts are less common in deciduous dentition because of the distinct biological cycle of primary teeth. ${ }^{3}$ They represent only $0.5-3.3 \%$ of the total number of cysts in the primary dentition. ${ }^{4}$ Most common etiological factor is due to sequelae of dental caries or due to traumatic dental injuries to the deciduous dentition. Radicular cysts arising from deciduous teeth are reported to occur in the age range of 3-19 years with a male predominance. The most commonly involved deciduous teeth are mandibular molars (67\%), maxillary molars (17\%) followed by anterior teeth. ${ }^{5}$

Radicular cysts when it is with deciduous teeth pose a diagnostic challenge as they mimic the same clinical, radiological, and histopathological features of dentigerous cyst. ${ }^{6}$ These cysts are often asymptomatic unless there is an acute inflammatory exacerbation and, therefore, these lesions are usually diagnosed on routine radiographic examination. Twenty-eight such cases have been recorded in the literature from 1898 to $1983 .^{7}$ It has been accounted that radicular cysts of 112 cases with deciduous teeth have been reported in the dental literature from 1927 to $2004 .^{8}$ Hereby describing a case report of infected radicular cyst of deciduous second molar mimicking the dentigerous cyst of the second premolar.

\section{Case Description}

A 5-year-old female patient reported to the Department of Pediatric and Preventive Dentistry, KLE VK Institute of Dental Sciences, Belagavi, Karnataka, India with the chief complaint of intraoral \begin{tabular}{l}
\hline \hline${ }^{1-6}$ Department of Pediatric and Preventive Dentistry, KLE VK Institute \\
of Dental Sciences, Belagavi, Karnataka, India \\
Corresponding Author: Shweta Kajjari, Department of Pediatric and \\
Preventive Dentistry, KLE VK Institute of Dental Sciences, Belagavi, \\
Karnataka, India, Phone: +919964525733 , e-mail: drshwetakajjari@ \\
gmail.com
\end{tabular}

How to cite this article: Kajjari S, Gowtham A, Meharwade P, et al. Infected Radicular Cyst of Deciduous Second Molar Mimicking Dentigerous Cyst of Second Premolar in a Young Child: A Rare Entity. Int J Clin Pediatr Dent 2021;14(3):434-437.

Source of support: Nil

Conflict of interest: None

swelling (Figs 1 and 2) and pain in the lower right back tooth region since 1 month. The patient was apparently alright 1 month back and noticed intraoral swelling of initial peanut size and gradually

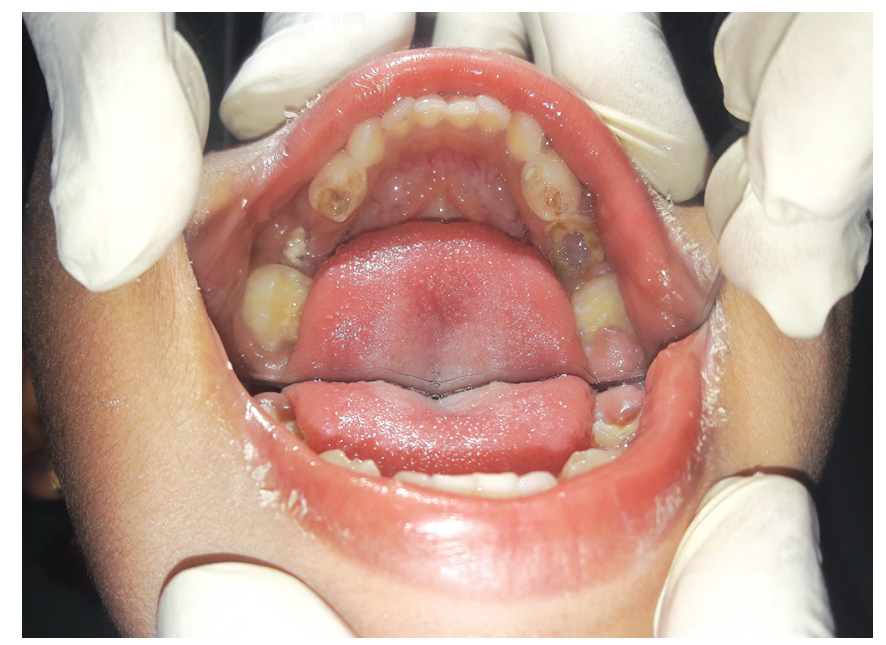

Fig. 1: Intraoral clinical picture of mandible

(c) Jaypee Brothers Medical Publishers. 2021 Open Access This article is distributed under the terms of the Creative Commons Attribution 4.0 International License (https://creativecommons.org/licenses/by-nc/4.0/), which permits unrestricted use, distribution, and non-commercial reproduction in anymedium, provided you give appropriate credit to the original author(s) and the source, provide a link to the Creative Commons license, and indicate if changes were made. The Creative Commons Public Domain Dedication waiver (http://creativecommons.org/publicdomain/zero/1.0/) applies to the data made available in this article, unless otherwise stated. 


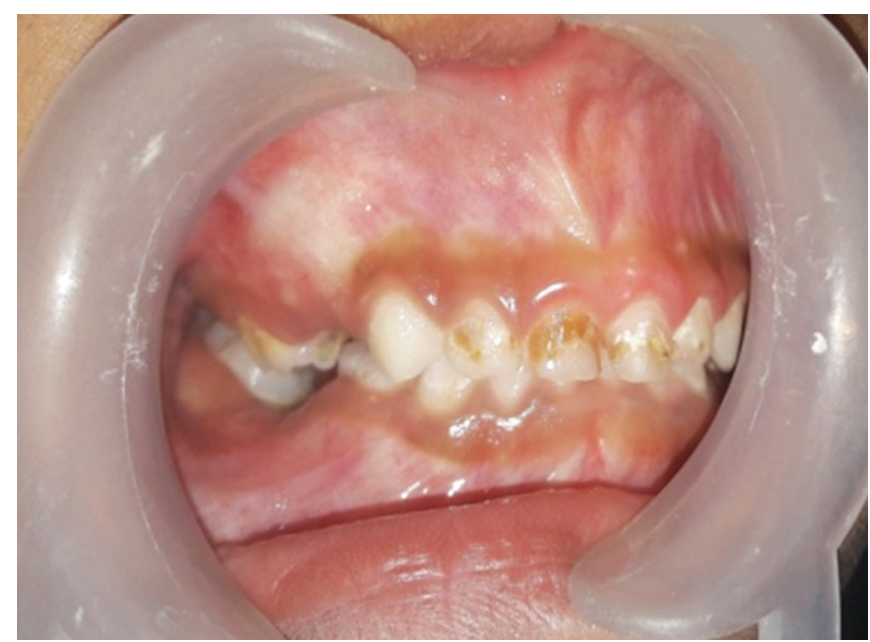

Fig. 2: Intraoral swelling wrt mandibular right posterior region

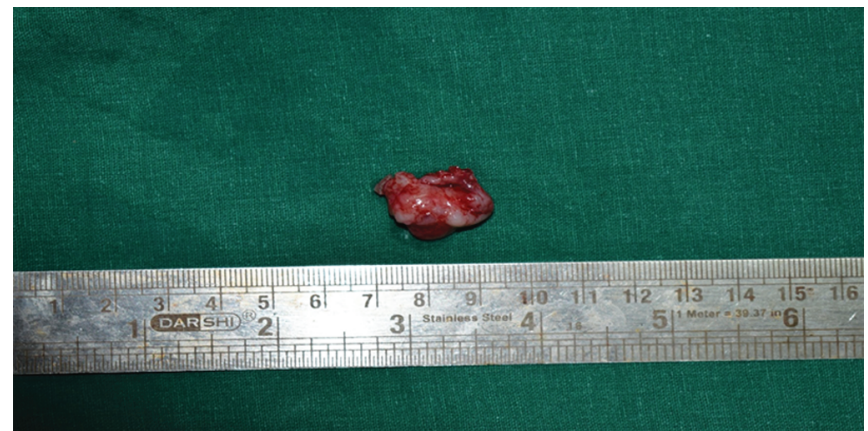

Fig. 4: Enucleated cyst along with 45

increased to the size of approximately $2 \times 3 \mathrm{~cm}$ oval size, which was tender on palpation along with intermittent nature of pain in the lower right back tooth region.

On general examination, there was no history of any hospitalization, and a history of trauma to the jaws was noted. Extraoral examination revealed there was no evidence of swelling. Intraoral examination revealed the mixed dentition stage. 74 and 84 were carious, 75 was grossly decayed. The patient gives a past dental history of gross destruction of 85 and exfoliated eventually. The buccal vestibule on the right back region shows obliteration and swelling was extended from the distal aspect of the mandibular right first molar to the mesial aspect of the mandibular right first permanent molar. The swelling was hard in consistency and tender on palpation. For further investigation, OPG was advised and it revealed unilocular radiolucency measuring about $2 \times 2 \mathrm{~cm}$ around the developing second premolar with a well-defined border, and radiolucency was seen which was extended up to the distal aspect of developing mesial root of permanent first molar (Fig. 3).

The provisional diagnosis was made based on clinical and radiographic examination as a dentigerous cyst.

All the surgical procedures were explained to the parents and written informed consent was taken for the same. Under aseptic conditions, surgical enucleation of the lesion along with the extraction of the $45,84,44$, and 46 and grossly decayed 75 was done (Figs 4 and 5). A surgical socket was treated with Corney's solution for 9 minutes then it was packed with gauze piece followed by suture placement (Figs 6 and 7). The specimen was sent for histopathological examination.

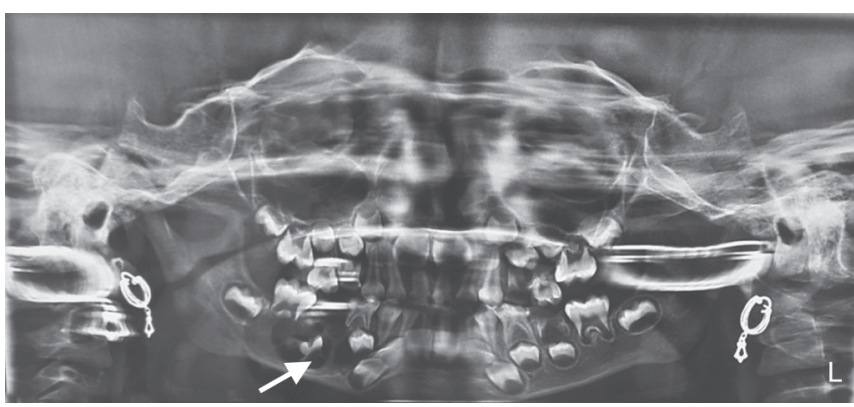

Fig. 3: OPG shows the radiolucent area around erupting second premolar

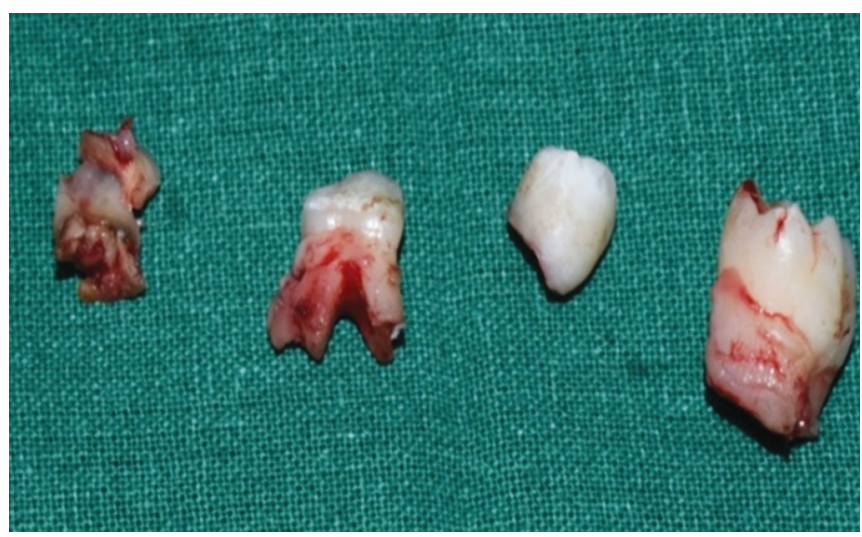

Fig. 5: Extraction of grossly decayed 75 and surgical removal of 84,44 and 46 along with the lesion

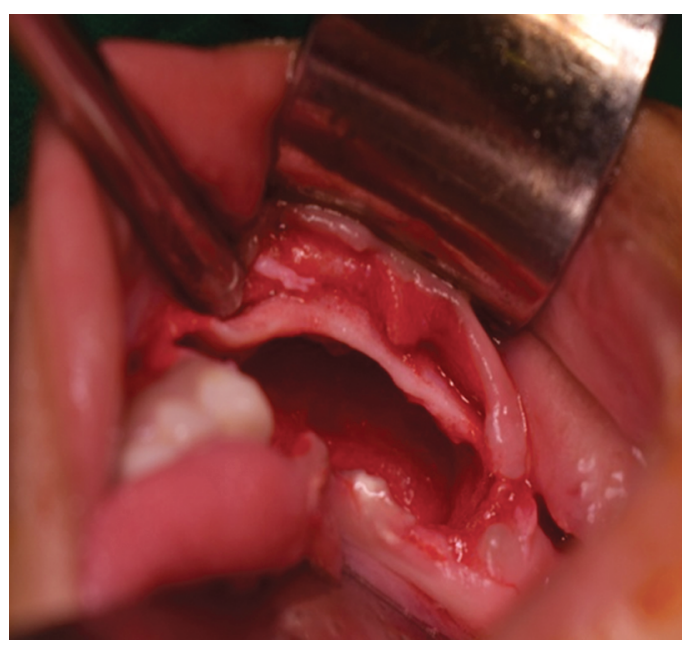

Fig. 6: Postoperative picture of the cystic cavity

Histopathological examination revealed a cystic lesion lined by squamous epithelium which is ulcerated at places (Fig. 8). The subepithelial tissue shows dense chronic inflammatory infiltrate (Fig. 9). Based on histopathological findings, the final diagnosis was made as an infected radicular cyst of the right posterior mandibular region.

Suture removal was done after 1 week, and the healing was uneventful. As the defect was larger in size, an obturator was planned to maintain the patency and for the eventful healing of the cavity, so upper and lower elastomeric impressions were made. Obturator was fabricated and delivered till further treatment was 


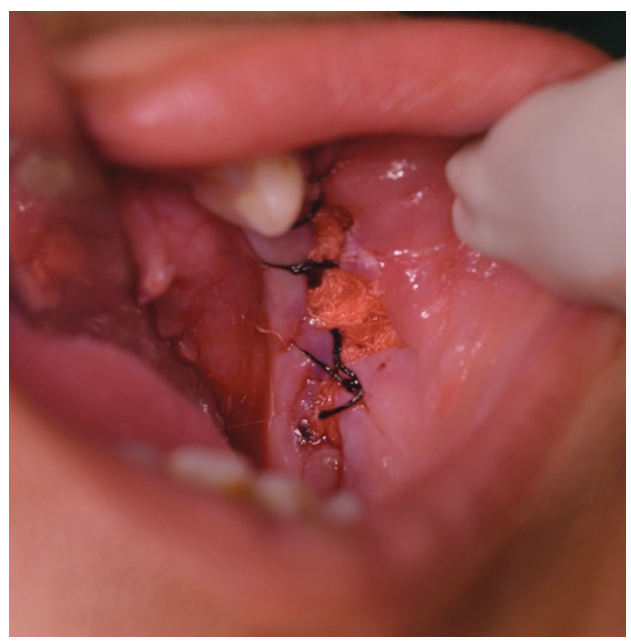

Fig. 7: Postoperative picture of the suture placement

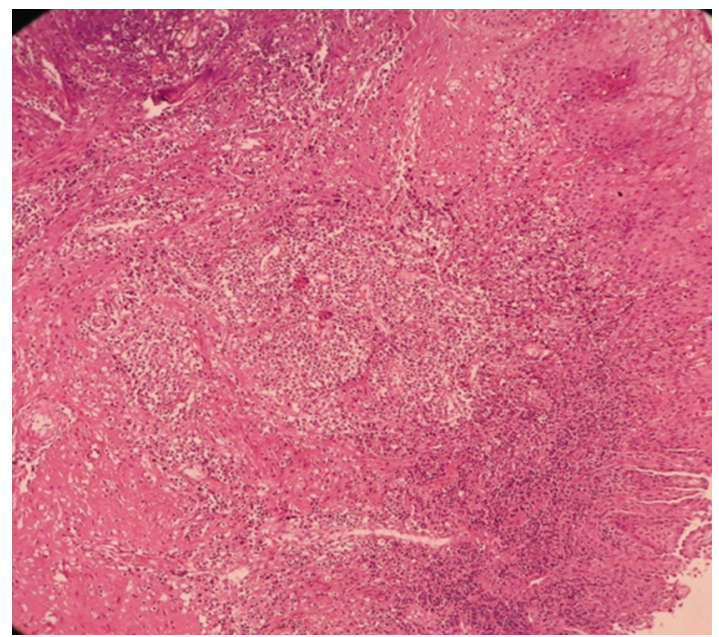

Fig. 9: Subepithelial tissue shows dense chronic inflammatory infiltration

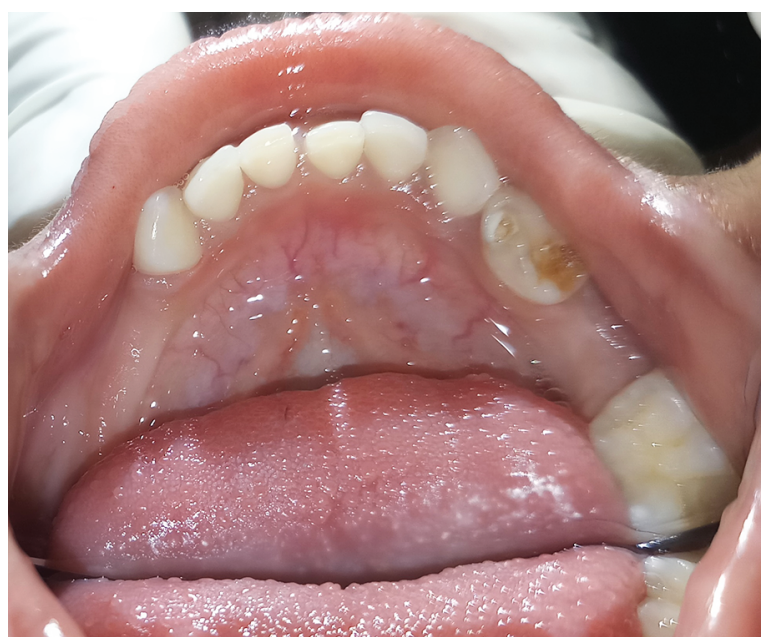

Fig. 11: After 3 months of follow-up

advocated (Fig. 10). The parents were instructed to irrigate the socket with betadine and saline solutions and to maintain proper oral hygiene. The patient was kept under follow up for every 15 days

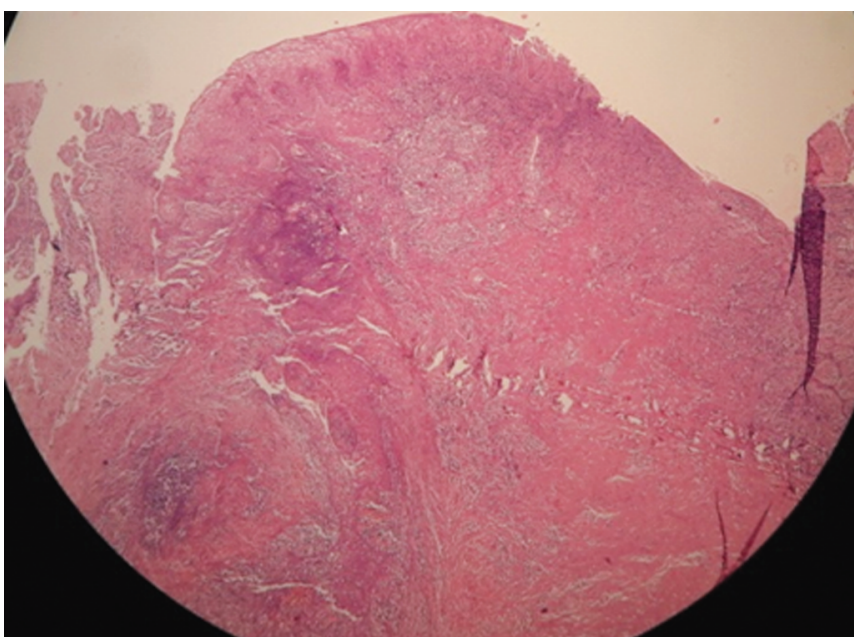

Fig. 8: Histopathological picture shows cystic lesion lined by squamous epithelium which is ulcerated at places

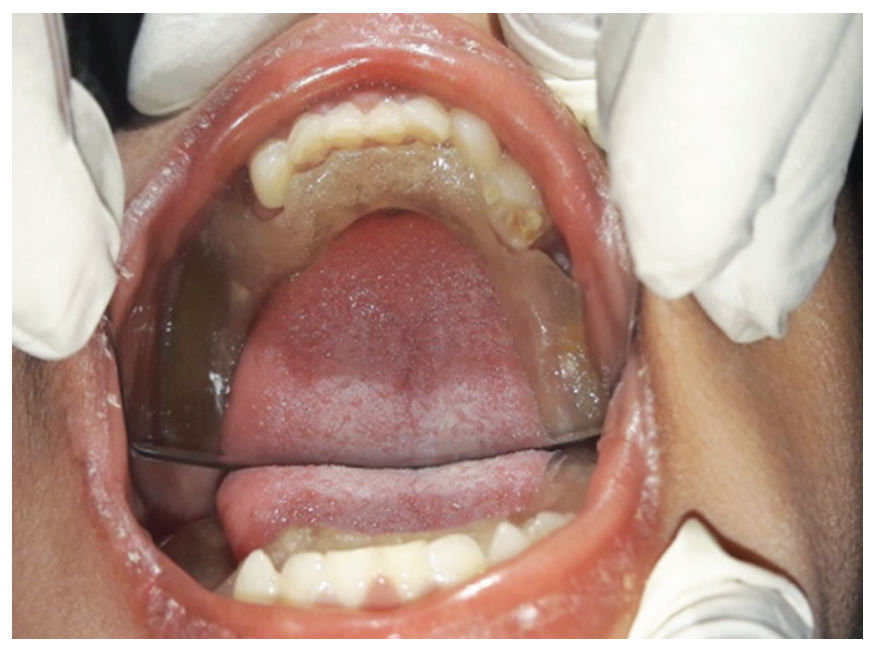

Fig. 10: Obturator insertion after suture removal

to check for healing and the adaptation of the obturator. After 3 months of follow-up, the surgical site shows proper closure of the wound healing and parents were satisfied with the treatment (Fig. 11).

\section{Discussion}

Radicular cysts which develop from the non-vital deciduous teeth are considered to be very rare, because of their distinct biological cycle and uncommon before the age of 10 years. ${ }^{9}$ According to Bernardi et al., the mechanism of radicular cyst includes pulpal necrosis, colonization, and proliferation of microorganisms within the root canal system, the release of bacteria toxins and inflammatory mediators into the periapical region, and a combination of factors involving epithelial-stromal interaction. The periradicular inflammation leads to the proliferation of epithelial cell rests. ${ }^{10}$

The radicular cyst has maxillary predominance in permanent teeth in contrast to that in deciduous it affects mandibular teeth because of the frequent caries occurrence in the lower arch. Sometimes radicular cysts which arise from deciduous teeth may resemble dentigerous cyst radiographically like in our present 
case. The provisional diagnosis was made as a dentigerous cyst as the OPG reveals developing second premolar with well-defined border and radiolucency was extended up to the distal aspect of developing mesial root of the permanent first molar. But the definitive diagnosis was made as a radicular cyst of mandibular second molar based on the histopathological findings.

The surgical treatment options for the cystic lesions of the jaws include either marsupialization or enucleation. The mode of the treatment mainly depends on the size and localization of the lesion, the bone integrity of the cystic wall, and its proximity to surrounding vital structures. ${ }^{11}$

Suggested treatment of choice for smaller radicular cyst in younger children is marsupialization if involved permanent tooth might be brought into its normal stage of the eruption, but the major disadvantage behind marsupialization is remnants of pathological tissue and its recurrence. ${ }^{12}$

In our present case, as the cystic lining was surrounded and firmly attached to the unerupted second premolar, enucleation of the cyst along with the involved tooth was the preferred option and also due to the extensive size of the lesion and apical displacement of the unerupted second premolar. Enucleation is done to minimize disfigurement and to avoid further postoperative complications.

An obturator was also required to decompress the cystic lesion, to maintain patency of the surgical opening, and to prevent the accumulation of food debris into the cystic cavity. ${ }^{13}$

\section{Conclusion}

This is a case presentation of an infected radicular cyst and successfully managed with the enucleation with recall visits for healing. Proper diagnosis and treatment plan place an important role in treating this type of case which mimics the dentigerous cyst radiographically. Follow-up visits are mandatory in such types of cases. A fixed type of prosthesis was planned for later rehabilitation of the missing teeth.

\section{References}

1. Latoo S, Shah AA, Jan SM, et al. Radicular cyst. JK Sci 2009;11(4):187189.

2. Ramakrishna Y, Verma D. Radicular cyst associated with a deciduous molar: a case report with unusual clinical presentation. J Indian Soc Pedod Prevent Dentis 2006;24(3):158-160. DOI: 10.4103/09704388.27899.

3. Toomarian L, Moshref M, Mirkarimi M, et al. Radicular cyst associated with a primary first molar: a case report. J Dent (Tehran) 2011;8(4): 213-217.

4. Shear M. Cyst of the oral region. 2nd ed., Butterworth-Heinemann Ltd; John Wright and Sons; 1983.

5. Elango I, Baweja DK, Noorani H, et al. Radicular cysts associated with deciduous molar following pulp therapy: a case report. Dent Res J 2008;5:95-98.

6. Wood RE, Nortjé CJ, Padayachee A, et al. Radicular cysts of primary teeth mimicking premolar dentigerous cysts: report of three cases. ASDC J Dent Child 1988;55(4):288-290.

7. Lustmann J, Shear M. Radicular cysts arising from deciduous teeth review of the literature and report of 23 cases. Int J Oral Surg 1985;14(2):153-161. DOI: 10.1016/s0300-9785(85)80087-9.

8. Nagata T, Nomura J, Matsumura Y, et al. Radicular cyst in deciduous tooth: a case report and review of literature. J Dent Child (Chic) 2008;75(1):80-84.

9. R. A Cawson-Cawson's essential of oral pathology and oral medicine; in Cysts of the Jaws;pg-115-123; 8th ed., Curcill Livingstone; pp. 237239.

10. Bernardi L, Visioli F, Nör C, et al. Radicular cyst: an update of the biological factors related to lining epithelium. J Endod 2015;41(12):1951-1961. DOI: 10.1016/j.joen.2015.08.036.

11. Shafer HL. Textbook of oral pathology. 6th ed., Amsterdam: Elsevier; 2006.

12. Peterson LJ, Ellis E, Hupp JR. Contemporary oral and maxillofacial surgery. 3rd ed., St Louis, MO: Mosby; 1998. p. 540.

13. Delbem AC, Cunha RF, Vieira AE, et al. Conservative treatment of a radicular cyst in a 5-year-old child: a case report. Int J Paediatr Dent 2003;13(6):447-450. DOI: 10.1046/j.1365-263x.2003. 00452.x. 